\title{
Consciência sintática no ensino fundamental: correlações com consciência fonológica, vocabulário, leitura e escrita
}

\author{
Alessandra Goturo Seabra Capovilla ${ }^{1}$ \\ Fernando César Capovilla \\ Joceli Verginia Toledo Soares
}

\begin{abstract}
Resumo
Habilidades metalingüísticas, como consciência fonológica e consciência sintática, são importantes à aquisição de leitura e escrita. Provas de consciência fonológica por escolha de figuras, escrita sob ditado, competência de leitura e vocabulário receptivo auditivo já se encontram disponíveis na bibliografia. Este estudo apresenta a Prova de Consciência Sintática e dados preliminares de validação com 204 crianças de 1a a 4a séries do ensino fundamental. Resultados mostraram efeito significativo da série escolar sobre o escore geral na Prova de Consciência Sintática e os escores específicos de seus quatro subtestes, mesmo depois de controlado o efeito da inteligência verbal usando o escore em vocabulário como covariante. O efeito da série escolar também foi significativo para os escores em consciência fonológica, competência de leitura, escrita sob ditado e vocabulário. Os escores gerais dos cinco testes mostraram-se positiva e significativamente intercorrelacionados, corroborando evidências bibliográficas sobre as relações entre leitura, escrita e habilidades metalingüísticas.

Palavras-Chave: Metalinguagem; Alfabetização; Fonologia; Léxico; Sintaxe.
\end{abstract}

\section{Syntactic awareness in elementary school: Correlation with phonological awareness, vocabulary, reading and spelling}

\begin{abstract}
Metalinguistic skills such as phonological awareness and syntactic awareness are important to reading and spelling acquisition. Standardized tests on phonological awareness, reading competence, spelling under dictation and receptive vocabulary in Brazilian Portuguese are already available in the literature. This paper presents a Syntactic Awareness Test, along with preliminary validation data from 204 first to fourth grade elementary school children. Children were tested in syntactic awareness, phonological awareness, reading, spelling and receptive vocabulary. Results showed significant effects of school grade upon Syntactic Awareness Test overall scores, as well as upon specific scores in all its four subtests, even after controlling for the effect of verbal intelligence by using vocabulary scores as covariant. Significant effects of school grade upon phonological awareness, reading, spelling and vocabulary were also found. Finally, overall scores in all five tests were positively interrelated, which gives support to published evidences about relationships holding among reading, spelling and metalinguistic skills.

Keywords: Metalanguage; Literacy; Phonology; Lexicon; Syntax.
\end{abstract}

Segundo Maluf (2003), leitura é uma atividade complexa que requer a habilidade metalingüística de refletir sobre a linguagem, tomando-a como objeto de conhecimento. Para Tunmer, Herriman e Nesdale (1988), consciência metalingüística é a habilidade de desempenhar operações mentais sobre o que é produzido pelos processos de compreensão de sentenças. Há diferenças importantes entre tal habilidade metalingüística e as lingüísticas, como a discriminação fonêmica (Kolinsky, no prelo). Para Gombert (2003), habilidades lingüísticas são não-conscientes e não-intencionais, e sua aprendizagem é natural, ao passo que as metalingüísticas são conscientes e intencionais, e sua aprendizagem requer instruções explícitas.
Habilidades precursoras das metalingüísticas podem ser observadas em crianças já a partir dos dois anos de idade (Gombert, 2003), como em autocorreções durante a fala de crianças com dois ou três anos de idade. Tais precursoras ainda não são habilidades metalingüísticas, mas epilingüísticas, pois não estão sob controle intencional da criança. Ou seja, enquanto o comportamento metalingüístico está sob controle consciente, o epilingüístico ainda não está.

Para Gombert (2003), apesar desses precursores da metalinguagem estarem presentes tão cedo no desenvolvimento infantil, a análise da estrutura formal da linguagem que caracteriza a metalinguagem, embora passível de realização na oralidade, é rara em tal

${ }^{1}$ Endereço para correspondência:

Programa de Estudos Pós-Graduados em Psicologia, Universidade São Francisco

Rua Alexandre Rodrigues Barbosa, 45 - Itatiba-SP - 13251-900 - Tel./fax: (11) 4534-8046

E-mail: alessandra.capovilla@saofrancisco.edu.br 
contexto, tendo seu desenvolvimento especialmente acelerado durante a aquisição da linguagem escrita. A metalinguagem pode ser subdividida na habilidade metafonológica de refletir sobre a estrutura fonológica da linguagem oral, e na habilidade metassintática de refletir sobre a estrutura sintática (i.e., morfológica e gramatical) da linguagem oral. Segundo Demont (1997), a metafonologia e a metassintaxe são especialmente importantes para a competência de leitura.

A importância da metafonologia (i.e., capacidade de identificar e manipular segmentos da fala, cf. Blischak, 1994) para a aquisição da linguagem escrita foi amplamente documentada (e.g., Jenkins \& Bowen, 1994; Wimmer, Landerl, Linortner \& Hummer, 1991), e se justifica porque a conscientização de que a fala possui uma estrutura fonêmica subjacente permite ao leitor usar um sistema gerativo que converte a ortografia em fonologia (Alegria, Leybaert \& Mousty, 1997), possibilitando a leitura de palavras novas regulares grafofonemicamente.

Segundo Grégoire e Piérart (1997), os processos de conscientização fonológica e de aquisição de leitura são recíprocos, facilitando-se mutuamente. Tal reciprocidade se deve à complexidade dos processos metafonológicos e de leitura, compostos de diversas sub-habilidades. Os estágios iniciais da consciência fonológica (consciência de rimas e sílabas) contribuem para desenvolver os estágios iniciais da leitura. Por sua vez, as habilidades iniciais de leitura contribuem para desenvolver habilidades metafonológicas mais complexas, como manipulação e transposição fonêmicas.

Conforme sumariado em Gombert (2003), enquanto a relação entre metafonologia e linguagem escrita está bem documentada, estudos sobre a relação entre metassintaxe e linguagem escrita ainda são incipientes. Metassintaxe pode ser definida como a habilidade de refletir sobre a estrutura sintática (i.e., morfológica e gramatical) da linguagem (Guimarães, 2002; Tunmer, 1990) e estudos como o de Tsang e Stokes (2001) têm sugerido que as dificuldades metassintáticas podem estar envolvidas em problemas de aquisição da leitura.

Segundo Gombert (2003), as primeiras evidências de comportamento genuinamente metassintático na criança podem ser encontradas por volta dos seis anos de idade, quando ela passa a se mostrar capaz de corrigir frases agramaticais. Assim como ocorre na relação entre a linguagem escrita e a consciência fonológica, a relação entre a linguagem escrita e a consciência sintática parece ser recíproca, sendo que os comportamentos epissintáticos em idade pré-escolar predispõem ao sucesso na aprendizagem da leitura, o que, por sua vez, promove maior desenvolvimento da reflexão sobre a sintaxe (Demont \& Gombert, 1996).
A consciência sintática é importante para a aquisição da linguagem escrita por diversas razões, como o fato de que a consciência sintática permite ao leitor ler palavras que ele não consegue decodificar, em razão da dificuldade pessoal em decodificar ou de dificuldades na própria palavra (irregularidades grafofonêmicas). Quando o leitor se depara com textos contendo palavras que não podem ser decodificadas facilmente, sua consciência sintática lhe permite recorrer às pistas sintáticas do texto para conseguir apreender o seu significado. Corroborando tal hipótese, Rego e Bryant (1993) demonstraram correlação positiva entre o desempenho em consciência sintática e o posterior desempenho na leitura de palavras com dificuldades ortográficas, ou seja, que não podem ser lidas corretamente com o uso exclusivo da decodificação.

Outra razão da relevância da consciência sintática para a leitura e a escrita consiste na importância do uso de pistas gramaticais para a compreensão de frases e textos (Bowey, 1986). Ou seja, além de contribuir para o reconhecimento de palavras, a reflexão sobre a sintaxe é essencial para a extração do significado do texto, uma vez que tal significado depende não somente da soma dos significados dos elementos lexicais individuais, mas também da forma pela qual tais elementos se articulam, o que é evidenciado por índices gramaticais como a ordem dos elementos na frase, a presença de palavras de função (e.g., preposições e artigos), a presença de morfemas gramaticais e a pontuação.

A consciência sintática tem sido tradicionalmente avaliada por tarefas orais como as de julgar frases (i.e., após ouvir frases corretas ou com incorreções morfêmicas, como em "O menina está dormindo.", ou incorreções de ordem, como em "Sapo o comeu o inseto.", dizer se estão ou não corretas do ponto de vista gramatical), corrigir frases (após ouvir frases com incorreções gramaticais, retificar essas incorreções, falando a frase corretamente), completar palavras em frases (adicionar terminações corretas em palavras de frases ou textos, como em "Eu comprei um ordi, João comprou dois or_.."), replicar erros (ao ouvir duas frases, uma incorreta e uma correta, repetir o erro da incorreta na correta; ex.: a partir de "Nós pegou os livros." e de "Nós gostamos do filme.", dizer "Nós gostou do filme.”) (Gombert, 2003; Tsang \& Stokes, 2001) e categorizar palavras (ao ouvir palavras, classificá-las como substantivos, verbos ou adjetivos) (Rego \& Buarque, 1997). Demont (1997) usou uma variação da tarefa de correção de frases, a correção de frases assemânticas $e$ agramaticais. Essa tarefa apresentava oralmente à criança frases com incorreções tanto semânticas quanto gramaticais, e a criança devia corrigir apenas o erro gramatical, ignorando o semântico. Por exemplo, após ouvir a frase "Cinderela é uma moça feio", a criança 
devia vertê-la para "Cinderela é uma moça feia". Essa prova tem a vantagem de avaliar a consciência sintática e verificar sua independência do conteúdo semântico, ou seja, avaliar se a criança é capaz de corrigir gramaticalmente a frase, mesmo que seu conteúdo permaneça inadequado. O desempenho nesta tarefa foi um preditor eficaz da leitura, sendo as correlações obtidas fortemente positivas (Demont, 1997).

De fato, diversos estudos sugerem que a consciência metalingüística geral, incluindo tanto a metafonológica quanto a metassintática, está correlacionada positiva e significativamente com o desempenho em leitura e em escrita (e.g., Gombert, 2003; Nation \& Snowling, 2000; Rego \& Buarque, 1997; Tunmer e colaboradores, 1988). Além disso, também há evidências de correlação positiva significativa entre metafonologia e metassintaxe (e.g., Demont, 1997). Isso mostra a importância de desenvolver instrumentos de avaliação das habilidades metalinguísticas, e de conduzir estudos para analisar as relações entre consciência sintática, consciência fonológica e linguagem escrita. Neste contexto, o presente estudo teve como objetivo apresentar a Prova de Consciência Sintática e dados preliminares de sua validação, investigando as relações entre consciência sintática, consciência fonológica, leitura e escrita em crianças de 1ạ a 4 a séries do ensino fundamental, buscando evidências de correlações entre tais habilidades, tendo controlado o efeito da inteligência verbal.

\section{Método}

\section{Participantes}

Participaram 204 crianças, sendo 57 da 1a série, 47 da 2a, 50 da 3a e 50 da 4a série do ensino fundamental de escola particular do bairro de Capão Redondo, em São Paulo, SP. Havia 104 meninos e 100 meninas, com idades variando de 6 anos e 4 meses a 10 anos e 6 meses.

\section{Instrumentos}

Prova de Consciência Fonológica por Figuras (PCFF). A Prova de Consciência Fonológica por Figuras PCFF (Capovilla \& Capovilla, 2004) avalia a habilidade da criança de manipular os sons da fala. Baseia-se na Prova de Consciência Fonológica Oral (Capovilla \& Capovilla, 2003) e é composta por nove subtestes, cada qual com dois itens de treino e cinco de teste. Cada item tem cinco desenhos, dentre os quais a criança deve escolher o que corresponde à palavra falada pelo aplicador. O subtestes são: 1) Rima: assinalar a figura cujo nome termina do mesmo modo como a palavra falada pelo aplicador; 2) Aliteração: assinalar a figura cujo nome começa como a palavra falada; 3) Adição Silábica: assinalar a figura cujo nome corresponde ao acréscimo de uma sílaba a uma palavra falada (ex.: PATO + SA no começo = SAPATO); 4) Adição Fonêmica: assinalar a figura cujo nome corresponde ao acréscimo de um fonema à palavra falada (ex.: ALA + /S/ no começo = SALA); 5) Subtração Silábica: assinalar a figura cujo nome corresponde à remoção de uma sílaba de palavra falada (ex: BOCA - /B/ = OCA); O) Subtração Fonêmica: assinalar a figura cujo nome corresponde à remoção de um fonema de palavra falada (ex.: MACACO - MA = CACO); 7) Transposição Silábica: assinalar a figura cujo nome corresponde à inversão da ordem das sílabas da palavra falada (ex.: LOBO - BOLO); 8) Transposição Fonêmica: assinalar a figura cujo nome corresponde à inversão da ordem dos fonemas da palavra falada (ex.: ÍRIS - SIRI); 9) Trocadilho: assinalar a figura cujo nome corresponde à inversão da ordem dos fonemas inicias de duas palavras (ex.: CULAR PORDA - PULAR CORDA).

O escore máximo na PCFF é de 45 acertos, com cinco acertos por subteste. Segundo Capovilla, Gütschow e Capovilla (2003), a fidedignidade da PCFF, em avaliação teste e reteste após 12 meses, obteve bom índice, com Pearson $r=0,69, p=0,000$. Como sumariado nesse mesmo estudo, a validade da PCFF foi estabelecida preliminarmente em diversos experimentos, com evidência de que o escore na PCFF é função direta da série e da idade desde a Pré-escola até a 2 a série, e as crianças que pontuam na faixa igual ou abaixo de 1 desvio padrão abaixo da média em leitura, conforme avaliada pelo Tecolesi, apresentam rebaixamento significativo do escore total na PCFF e em cada um dos subtestes.

Prova de Consciência Sintática (PCS). A Prova de Consciência Sintática - PCS (Capovilla \& Capovilla, no prelo) é baseada nas provas de Demont (1997), Nation e Snowling (2000), Rego e Buarque (1997) e Tsang e Stokes (2001). Contém 4 subtestes: 1) Julgamento Gramatical: a criança deve julgar a gramaticalidade de 20 frases, sendo metade gramaticais e metade agramaticais. Dentre as agramaticais, há frases com anomalias morfêmicas e com inversões de ordem; 2) Correção Gramatical: corrigir frases gramaticalmente incorretas, sendo metade com anomalias morfêmicas e metade com inversões de ordem; 3) Correção Gramatical de Frases Agramaticais e Assemânticas: diante de frases com incorreções tanto semânticas quanto gramaticais, corrigir o erro gramatical sem alterar o erro semântico; 4) Categorização de Palavras: a criança deve categorizar palavras, dizendo se uma determinada palavra é substantivo, verbo ou adjetivo (cf. Rego \& Buarque, 1997). A PCS completa, com as instruções, itens de treino e de teste, encontra-se no Anexo 1. O escore total corresponde à soma dos acertos em cada subteste, até o máximo possível de 55 acertos. Como neste estudo a PCS foi aplicada pela primeira vez, ainda não há dados sobre sua fidedignidade ou validade.

Teste de Competência de Leitura Silenciosa 
(Tecolesi). O Teste de Competência de Leitura Silenciosa - Tecolesi (Capovilla \& Capovilla, 2004) avalia a competência de leitura silenciosa. Possui oito tentativas de treino e 70 de teste, cada qual com um par composto de uma figura e um item escrito. A tarefa consiste em circundar os pares corretos e cruzar os incorretos. Há sete tipos de pares ordenados aleatoriamente, com dez itens de cada tipo: 1) Palavras corretas regulares, como FADA sob figura de fada; 2) Palavras corretas irregulares, como TÁxI sob figura de táxi; 3) Palavras com incorreção semântica, como TREM sob figura de ônibus; 4) Pseudo-palavras com trocas visuais, como CAEBÇA sob figura de cabeça; 5) Pseudopalavras com trocas fonológicas, CANCURU sob figura de canguru; 6) Pseudopalavras homófonas, PÁÇARU sob figura de pássaro; 7) Pseudopalavras estranhas, como RASSUNO sob figura de mão. Os pares figura-escrita compostos de palavras corretas devem ser aceitos; aqueles compostos de pseudopalavras ou palavras com incorreção semântica devem ser rejeitados. Como explicado em Capovilla e Capovilla (2004), o padrão de erros nos sete tipos de pares revela as estratégias de leitura funcionais e as disfuncionais.

O escore máximo é de 70 acertos. Segundo Capovilla, Gütschow e Capovilla (2003), a fidedignidade do Tecolesi, em avaliação teste e reteste após 12 meses, obteve índice Pearson $r=0,50, p=0,000$. Como sumariado nesse estudo, a validade do Tecolesi em mapear o processamento de leitura em crianças foi estabelecida preliminarmente em diversos estudos, com evidência de que o teste é capaz de discriminar entre séries sucessivas da pré-escola à 3 a série, e as crianças que pontuam na faixa igual ou abaixo de 1 desvio padrão abaixo da média no Tecolesi apresentam maior dificuldade em discriminar fonemas, menor velocidade de processamento fonológico e menor capacidade de memória de trabalho fonológica, consciência fonológica, vocabulário, ditado e desenho de memória.

Subteste de Escrita sob Ditado do Internacional Dyslexia Test (IDT). O Internacional Dyslexia Test IDT (Capovilla, Smythe, Capovilla \& Everatt, 2001) é composto de vários subtestes e avalia diferentes habilidades cognitivas. Neste estudo o subteste de Escrita sob Ditado foi aplicado em situação coletiva, em que o examinador ditava 30 palavras e 10 não-palavras para a criança escrever. O escore máximo é de 40 acertos. Segundo Capovilla, Gütschow e Capovilla (2003), esse subteste tem boa fidedignidade, com índice Pearson $r=$ 0,78 e $p=0,000$ em avaliação teste e reteste após 12 meses, e boa validade, estabelecida preliminarmente em diversos estudos, em que o escore de Escrita sob Ditado foi função direta da idade e do nível escolar entre préescola a 3 a série, estando positiva e significativamente correlacionado com os escores em leitura no Tecolesi.
Teste de Vocabulário de Figuras USP (Tvfusp). O Teste de Vocabulário por Figuras USP - Tvfusp (Capovilla, Viggiano e colaboradores, 2004) avalia o vocabulário receptivo auditivo, isto é, a habilidade de compreender palavras faladas. Apresenta 139 pranchas de teste, ordenadas por dificuldade crescente, cada qual com cinco desenhos. A tarefa consiste em selecionar, dentre as figuras alternativas, aquela que melhor corresponde à palavra falada pelo examinador. $\mathrm{O}$ escore máximo é de 139 acertos. Conforme sumariado em Capovilla, Gütschow e Capovilla (2003), a validade concorrente do Tvfusp foi estabelecida preliminarmente por comparação com o Teste de Vocabulário por Figuras Peabody - Versão Brasileira (Dunn, Dunn, Capovilla \& Capovilla, 2004)

\section{Procedimento}

As 204 crianças foram avaliadas em todos os cinco instrumentos descritos durante o período escolar regular. A PCS foi aplicada individualmente em salas reservadas da escola e os demais instrumentos foram aplicados na própria sala de aula, mantendo um intervalo de uma semana entre cada aplicação.

\section{Resultados}

A Tabela 1 sumaria os escores médios e os erros padrão (entre parênteses) de cada série escolar na Prova de Consciência Sintática como um todo e em cada subteste. Anova do efeito da série escolar sobre o escore total na PCS revelou efeito significativo de série, $F(3,196)=31,9, p=0,000$. Análises de comparação de pares com o teste Fisher LSD revelaram aumento do escore de 1a a 2a , 3a e 4a séries; e de 2a e 3a a 4a série. Ou seja, o escore na PCS aumentou sistematicamente de 1 a a 2a, e de 3a a 4a séries. Diferenças não significativas não se encontram descritas. Anovas do efeito da série sobre os escores em cada um dos quatro subtestes da PCS também foram conduzidas separadamente para cada subteste. Essas Anovas revelaram efeitos significativos da série sobre o desempenho de Julgamento Gramatical, $F(3,196)=4,8, p=0,003$; Correção Gramatical, $F(3$, $196)=6,5, p=0,000$; Correção Gramatical de Frases Agramaticais e Assemânticas, $F(3,196)=12,5, p=$ 0,000; e Categorização de Palavras, $F(3,196)=21,0, p$ $=0,000$. Análises de Fisher LSD revelaram aumentos nos escores em: Julgamento Gramatical de 1a a 3a e 4a séries, e de 2a a 4a série; Correção Gramatical de 1a a 2aㅡ, 3a e 4a séries, e de 2a a 4a série; Correção Gramatical de Frases Agramaticais e Assemânticas de 1a a 2a , 3a e 4a séries; e Categorização de Palavras de 1a a 2a , 3 $\underline{a}$ e 4a séries, de 2a e 3a a 4a a série. Assim, o padrão em Categorização de Palavras foi o mais semelhante ao padrão geral na PCS.

Psico-USF, v. 9, n. 1, p. 39-47, Jan./Jun. 2004 
Tabela 1 - Escore médio e erro padrão (entre parênteses) por série escolar em consciência sintática (PCS) e subtestes de julgamento gramatical (JG), correção gramatical (CG), correção gramatical de frases agramaticais e assemânticas (CGFAA), e categorização de palavras (CP)

\begin{tabular}{ccccc}
\hline & 1a Série & 2a Série & 3a Série & 4a Série \\
\hline PCS & $43,54(0,58)$ & $47,41(0,64)$ & $47,72(0,64)$ & $51,86(0,62)$ \\
JG & $19,05(0,15)$ & $19,30(0,16)$ & $19,72(0,16)$ & $19,76(0,16)$ \\
CG & $7,72(0,17)$ & $8,26(0,19)$ & $8,36(0,19)$ & $8,80(0,18)$ \\
CGFAA & $7,60(0,19)$ & $8,67(0,21)$ & $8,96(0,21)$ & $9,16(0,20)$ \\
CP & $9,18(0,43)$ & $11,17(0,48)$ & $10,68(0,48)$ & $14,14(0,46)$ \\
\hline
\end{tabular}

O efeito da série escolar sobre os desempenhos na PCS continuou significativo mesmo após controlar o efeito da inteligência verbal usando o escore no Tvfusp como covariante. Ancova do efeito da série sobre o escore total na PCS, tendo o escore no Tvfusp como covariante, revelou efeito de série, $F(3,195)=23,40, p=0,000$. Ancovas separadas para cada subteste, sempre tendo o escore no Tvfusp como covariante, revelaram efeitos de série sobre escores em Julgamento Gramatical, $F(3,196)=$ $2,80, p=0,041$; Correção Gramatical, $F(3,196)=4,98, p$ $=0,002$; Correção Gramatical de Frases Agramaticais e Assemânticas, $F(3,196)=9,37, p=0,000$; e Categorização de Palavras, $F(3,196)=16,43, p=0,000$. Análises de Fisher LSD subseqüentes às Ancovas revelaram dados idênticos aos das análises subseqüentes às Anovas, já descritos.

A Tabela 2 sumaria os escores médios e os erros padrão de cada série escolar em PCFF, Tecolesi,
Ditado-IDT e Tvfusp. Anovas do efeito da série sobre cada prova, separadamente, revelaram efeitos significativos para PCFF, $F(3,196)=10,37, p=0,000$; Tecolesi, $F$ $(3,196)=10,22, p=0,000$; Ditado-IDT, $F(3,182)=$ $22,88, p=0,000$; e Tvfusp, $F(3,196)=18,54, p=0,000$. Análises de Fisher LSD revelaram aumento significativo em PCFF de 1a a 2a $\underline{a}$, $\underline{a}$ e $4 \underline{a}$ séries, e de 2a a $3 \underline{a}$ série. Ou seja, a PCFF identificou aumento sistemático da habilidade metafonológica de 1a a 2 a série, e de 2 a a $3 \underline{a}$ série. Revelaram também aumento em Tecolesi de 1a a 2a , 3a e e $\underline{a}$ séries, e de 2 e e 3 a 4 a série. Ou seja, o Tecolesi identificou aumento da competência de leitura de 1a a a $2 \underline{a}$ série, e de $3 \underline{a}$ a $4 \underline{a}$ série. Revelaram, ainda, aumentos significativos em DitadoIDT e em Tvfusp de 1a a 2a, $3 \underline{a}$ e $4 \underline{a}$ séries, e de 2a a $3 \underline{a}$ e $4 \underline{a}$ séries. Ou seja, assim como a consciência fonológica, a escrita sob ditado e o vocabulário receptivo aumentaram sistematicamente de $1 \underline{a}$ a $2 \underline{a}$ série, e de $2 \underline{a}$ a $3 \underline{a}$ série.

Tabela 2 - Escore médio e erro padrão (entre parênteses) por série escolar em consciência fonológica por figuras (PCFF), competência de leitura silenciosa (Tecolesi), escrita sob ditado do IDT (Ditado-IDT) e no vocabulário por figuras USP (Tvfusp)

\begin{tabular}{ccccc}
\hline & 1aㅗ Série & 2aㅗ Série & 3a Série & 4a Série \\
\hline PCFF & $39,51(0,39)$ & $41,02(0,43)$ & $42,43(0,43)$ & $42,02(0,41)$ \\
Tecolesi & $61,37(0,89)$ & $64,48(0,99)$ & $65,53(0,98)$ & $68,46(0,95)$ \\
Ditado-IDT & $24,68(0,66)$ & $27,06(0,87)$ & $30,79(0,73)$ & $31,92(0,71)$ \\
Tvfusp & $119,68(1,30)$ & $127,13(1,44)$ & $132,28(1,43)$ & $131,46(0,39)$ \\
\hline
\end{tabular}

Para verificar as relações entre o escore em consciência sintática e os escores em consciência fonológica, leitura e escrita, foram conduzidas análises de correlação de Pearson entre, de um lado, os escores na PCS (total e em cada subteste) e, de outro lado, os escores nos demais instrumentos para as quatro séries como um todo. Conforme a Tabela 3, que sumaria os coeficientes de correlação e os dados de significância, houve correlação positiva significativa entre o desempenho de consciência sintática, tanto em termos de escore geral quanto em cada subteste, e os desempenhos em consciência fonológica, leitura e escrita.

Tabela 3 - Coeficientes de correlação de Pearson (r) e significância estatística (p) entre parênteses. Intercorrelações de consciência sintática (PCS) e subtestes de julgamento gramatical (JG), correção gramatical (CG), correção gramatical de frases agramaticais e assemânticas (CGFAA), e categorização de palavras (CP), com consciência fonológica por figuras (PCFF), na competência de leitura silenciosa (Tecolesi), e escrita sob ditado do IDT (Ditado-IDT)

\begin{tabular}{cccc}
\hline & PCFF & Tecolesi & Ditado-IDT \\
\hline PCS & $0,38(0,000)$ & $0,42(0,000)$ & $0,43(0,000)$ \\
JG & $0,24(0,001)$ & $0,23(0,001)$ & $0,15(0,036)$ \\
CG & $0,24(0,000)$ & $0,20(0,004)$ & $0,22(0,003)$ \\
CGFAA & $0,25(0,000)$ & $0,30(0,000)$ & $0,27(0,000)$ \\
CP & $0,26(0,000)$ & $0,33(0,000)$ & $0,37(0,000)$ \\
\hline
\end{tabular}


Finalmente, para verificar as correlações entre todas as cinco habilidades avaliadas neste estudo (i.e., consciência sintática, consciência fonológica, leitura, escrita e vocabulário), foram conduzidas análises de correlação de Pearson entre os escores totais nos cinco instrumentos. A Tabela 4 sumaria os coeficientes de correlação e os dados de significância. Conforme a tabela, em que pese a relativamente baixa correlação entre Julgamento Gramatical e Ditado, todas as interrelações mostraram-se positivas e significativas.

Tabela 4 - Coeficientes de correlação de Pearson $(r)$ entre os escores nos vários subtestes, com significância estatística $(p)$ entre parênteses

\begin{tabular}{ccccc}
\hline & PCS & PCFF & Tecolesi & Ditado-IDT \\
\hline PCFF & $0,38(0,000)$ & --- & --- & --- \\
Tecolesi & $0,42(0,000)$ & $0,15(0,034)$ & --- & --- \\
Ditado-IDT & $0,43(0,000)$ & $0,40(0,000)$ & $0,24(0,001)$ & --- \\
Tvfusp & $0,31(0,000)$ & $0,27(0,000)$ & $0,25(0,000)$ & $0,24(0,001)$ \\
\hline
\end{tabular}

\section{Discussão}

Os presentes resultados corroboram evidências bibliográficas sobre a correlação entre leitura, escrita, consciência sintática e consciência fonológica (e.g., Demont \& Gombert, 1996; Gombert, 2003; Maluf \& Barrera, 1997; Rego \& Buarque, 1997). Para Demont (1997), a correlação entre as habilidades metalingüísticas (i.e., consciências sintática e fonológica) sugere a existência de um fator comum ou mesmo tipo de competência. No estudo de Demont (1997), os desempenhos em metassintaxe e em metafonologia, avaliados na pré-escola, compuseram um fator que explicou $40,1 \%$ da variância em um teste de leitura aplicado 10 meses depois, $34,5 \%$ da variância 20 meses depois, e $30,2 \%$ da variância 27 meses depois.

A correlação entre habilidades metalingüísticas, leitura e escrita também corroborou a bibliografia (Bowey, 1994; Gombert, 2003). Conforme evidenciado em outros estudos (e.g., Demont, 1997; Demont \& Gombert, 1996; Gaux \& Gombert, 1999; Tunmer, 1990), tal correlação constitui uma relação causal recíproca. Ou seja, as habilidades metassintáticas e metafonológicas mais precoces e menos refinadas predizem o sucesso ulterior na aquisição da linguagem escrita, assim como a introdução a um sistema de escrita alfabético promove o desenvolvimento de habilidades metafonológicas e metassintáticas complexas.

Finalmente, o estudo possibilitou uma validação preliminar da Prova de Consciência Sintática, por meio das evidências de efeito de série escolar sobre o escore total e em cada subteste da PCS e de correlações positivas significativas entre os desempenhos na PCS e em testes de leitura, escrita e consciência fonológica. Em estudos futuros a PCS será normatizada para permitir aprimorar a compreensão de dificuldades de aquisição de leitura e escrita.

\section{Referências}

Alegria, J., Leybaert, J. \& Mousty, P. (1997). Aquisição da leitura e distúrbios associados: avaliação, tratamento e teoria. Em J. Grégoire \& B. Piérart (Orgs.). Avaliação dos problemas de leitura: os novos modelos teóricos e suas implicaçôes diagnósticas. (pp. 105-124). Porto Alegre, RS: Artes Médicas.

Blischak, D. M. (1994). Phonologic awareness: Implications for individuals with little or no functional speech. Augmentative and Alternative Communication, 10, 245-254.

Bowey, J. A. (1986). Syntactic awareness in relation to reading skill and ongoing reading comprehension monitoring. Journal of Experimental Child Psychology, 41, 282-299.

Bowey, J. A. (1994). Phonological sensitivity in novice readers and nonreaders. Journal of Experimental Child Psychology, 58, 134-159.

Capovilla, A. G. S. \& Capovilla, F. C. (2003). Problemas de leitura e escrita: como identificar, prevenir e remediar numa abordagem fônica. (3a. ed.). São Paulo, SP: Memnon.

Capovilla, A. G. S. \& Capovilla, F. C. (2004). Alfabetização: método fônico. (3a. ed.). São Paulo, SP: Memnon.

Capovilla, A. G. S. \& Capovilla, F. C. (no prelo). Prova de Consciência Sintática. Ciência cognitiva: teoria, pesquisa e aplicação.

Capovilla, A. G. S., Gütschow, C. R. D. \& Capovilla, F. C. (2003). Instrumentos de avaliação de habilidades cognitivas relacionadas à aquisição de leitura e escrita: análise de validade e fidedignidade. Em A. G. S. Capovilla (Org.). Avaliação e intervenção em habilidades metafonológicas e de leitura e escrita. São Paulo, SP: Memnon.

Capovilla, A. G. S., Smythe, I., Capovilla, F. C. \& Everatt, J. (2001). Adaptação brasileira do Interna- 
tional Dyslexia Test: perfil cognitivo de crianças com escrita pobre. Temas sobre Desenvolvimento, 10(57), 30-37.

Capovilla, F. C. \& Capovilla, A. G. S. (2004). Research on the role of phonology, orthography and cognitive skills upon reading, spelling and dyslexia in Brazilian Portuguese. Em I. Smythe, J. Everatt \& R. Salter (Orgs.). International Book on Dyslexia: A cross language comparison and practice guide. (pp. 159-172). London, UK: John Wiley \& Sons, Ltd.

Capovilla, F. C., Viggiano, K. Q., Capovilla, A. G. S., Raphael, W. D., Bidá, M. R. \& Mauricio, A. C. (2004). Como avaliar o desenvolvimento da compreensão de sinais da Libras em surdos do ensino fundamental ao médio: Versão 1.1 do Teste de Vocabulário Receptivo de Sinais da Libras (TVRSL1.1) validada e normatizada para aplicação com sinalização ao vivo. Em F. Capovilla, W. Raphael (Orgs.). Enciclopédia da Lingua de Sinais Brasileira: o mundo do surdo em Libras, Vol. 2. São Paulo, SP: Edusp, Vitae, Feneis, CNPq.

Demont, E. (1997). Consciência fonológica, consciência sintática: que papel (ou papéis) desempenha na aprendizagem eficaz da leitura? Em J. Gregóire \& B. Piérart (Orgs.). Avaliação dos problemas de leitura: os novos modelos teóricos e suas implicacoôes diagnósticas. (pp. 189-202). Porto Alegre, RS: Artes Médicas.

Demont, E. \& Gombert, J. E. (1996). Phonological awareness as a predictor of recoding skills and syntactic awareness as a predictor of comprehension skills. British Journal of Educational Psychology, 66, 315-332.

Dunn, L. M., Dunn, D., Capovilla, F. C. \& Capovilla, A. G. S. (2004). Teste de Vocabulário por Figuras Peabody versão brasileira. São Paulo, SP: Casa do Psicólogo.

Gaux, C. \& Gombert, J. E. (1999). Implicit and explicit syntactic knowledge and reading in pre-adolescents. British Journal of Developmental Psychology, 17, 169-188.

Gombert, J. E. (2003). Atividades metalingüísticas e aprendizagem da leitura. Em M. R. Maluf (Org.). Metalinguagem e aquisição da escrita: contribuiçōes da pesquisa para a prática da alfabetização. (pp. 19-64). São Paulo, SP: Casa do Psicólogo.

Grégoire, J. \& Piérart, B. (1997). Avaliação dos problemas de leitura: os novos modelos teóricos e suas implicacões diagnósticas. Porto Alegre, RS: Artes Médicas.

Guimarães, S. R. K. (2002). Dificuldades no desenvolvimento da lectoescrita: o papel das habilidades meta- lingüísticas. Psicologia: Teoria e Pesquisa, 18(3), 247-259.

Jenkins, R. \& Bowen, L. (1994). Facilitating development of preliterate children's phonological abilities. Topics in Language Disorders, 14(2), 26-39.

Kolinsky, R. (no prelo). Schooling and alphabetization effects on the development of visual "metacognition". Em F. C. Capovilla (Org.). Desenvolvimento da cognição e linguagem: avaliação, teoria e intervenção. São Paulo, SP: Casa do Psicólogo.

Maluf, M. R. (2003). Apresentação. Em M. R. Maluf (Org.). Metalinguagem e aquisição da escrita: contribuições da pesquisa para a prática da alfabetização. (pp. 9-18). São Paulo, SP: Casa do Psicólogo.

Maluf, M. R. \& Barrera, S. D. (1997). Consciência fonológica e linguagem escrita em pré-escolares. Psicologia: Reflexão e Crítica, 10(1), 125-145.

Nation, K. \& Snowling, M. J. (2000). Factors influencing syntactic awareness skills in normal readers and poor comprehenders. Applied Psycholinguistics, 21(2), 229-241.

Rego, L. L. B. \& Bryant, P. E. (1993). The connection between phonological, syntactic and semantic skills and children's reading and spelling. European Journal of Psychology of Education, 8(3), 235-246.

Rego, L. L. B. \& Buarque, L. L. (1997). Consciência sintática, consciência fonológica e aquisição de regras ortográficas. Psicologia: Reflexão e Crítica, 10(2), 199-217.

Tsang, K. K. S. \& Stokes, S. F. (2001). Syntactic awareness of Cantonese-speaking children. Journal of Child Language, 28(3), 703-739.

Tunmer, W. E. (1990). The role of language prediction skills in beginning reading. New Zealand Journal of Educational Studies, 25, 95-114.

Tunmer, W. E., Herriman, M. L. \& Nesdale, A. R. (1988). Metalinguistic abilities and beginning reading. Reading Research Quarterly, 23, 134-158.

Wimmer, H., Landerl, K., Linortner, R. \& Hummer, P. (1991). The relationship of phonemic awareness to reading acquisition: More consequence than precondition but still important. Cognition, 40, 219-249.

Enviado em março de 2004 Reformulado em maio de 2004 Aprovado em maio de 2004 


\section{Anexo 1 \\ Prova de Consciência Sintática}

1) Julgamento gramatical: Julgar a gramaticalidade de 20 frases, sendo metade destas gramaticais e metade agramaticais. Dentre as frases agramaticais, há frases com anomalias morfêmicas (ex.: "Maria vestiu seu camisa") ou inversões de ordem (ex.: "Está a quente comida").

Instruções: Eu vou dizer algumas frases para você. Algumas estarão corretas e outras estarão erradas. Quero que você me diga se a frase está certa ou errada. Por exemplo, a frase "O menino comprou uma doce" está errada, porque nós não falamos "uma doce", mas sim "um doce". A frase "O menino comprou um doce" está correta. Vou dar outro exemplo: a frase "Está o gelado suco" está errada, porque as palavras estão na ordem errada. O certo é: “O suco está gelado". Entendeu? Então as frases podem estar certas ou erradas, e podem estar erradas porque uma palavra está errada ou porque as palavras estão fora de ordem. Agora vou falar outras frases e você me dirá se estão certas ou erradas.

Itens de treino (aplicador pergunta e, após a resposta da criança, deve ajudar a criança explicitando por que a frase está certa ou errada):

a) Eu vamos ao parque. (Após a resposta da criança, dizer: A frase está errada, porque nós não falamos "Eu vamos ao parque", mas sim "Eu vou ao parque".)

b) Cachorro é preto. (Após a resposta da criança, dizer: A frase está certa!)

c) É carro aquele meu. (Após a resposta da criança, dizer: A frase está errada, porque está fora de ordem. Não é "é carro aquele meu", mas sim "Aquele é meu carro".)

Agora você continua sozinho, eu não vou mais ajudar.

Itens de teste (aplicador anota a resposta da criança, mas não deve mais ajudar. Para facilitar a correção pelo aplicador, encontram-se assinaladas, entre parênteses, as frases que apresentam incorreções, sendo IM = incorreção morfêmica e $\mathrm{IO}=$ incorreção de ordem):

1. A mulher está bonito. (IM)

2. As flores são brancas.

3. Escola gosto eu da. (IO)

5. Maria gosta de sorvete. 15. Meu irmã bebeu leite. (IM)

6.Papai saiu para trabalhar. 16. Os meninos estão brincando.

7.Meus azuis são olhos. (IO) 17. Andou de ela carro. (IO)

8. Ontem eu comi macarrão. $\quad$ 18. Nós comi uma maçã. (IM)

9. A fruta são gostosas. (IM) 19. Esse bebê está dormindo.

10. É professora minha legal.(IO) 20. Eu gosto de matemática.

2) Correção gramatical: Neste subteste, a criança deverá corrigir frases agramaticais.

Instruções: Agora eu direi algumas frases erradas e você tem que corrigir, deixando as frases corretas. Por exemplo, se eu disser: "Minha gata são branca", você tem que corrigir dizendo: "Minha gata é branca". Se eu disser: "O alto é menino", você tem que corrigir dizendo: "O menino é alto". Agora eu vou falar outras frases e você vai corrigi-las.

Itens de treino (aplicador pergunta e, após a resposta, explica como fica a frase correta):

a) Eu gosto do professora. (Após a resposta da criança, dizer: A frase está errada porque não falamos "do professora". A frase correta é "Eu gosto da professora".)

b) Terminei a lição eu. (Após a resposta da criança, dizer: A frase está errada, porque está fora de ordem. A frase correta é "Eu terminei a lição".)

Agora você continua sozinho, eu não vou mais ajudar.

Itens de teste (aplicador anota a resposta da criança, mas não deve mais ajudar):
1. Futebol o joga menino.
6. Sua blusa está sujo.
2. Lápis apontei eu.
7. Guardou o brinquedo ela.
8. Minha tia comeram pizza.
3. A sol está brilhando.
9. Suco o bebi eu.
5. Ele gostamos de bombom.
10. Avião são rápidos.

3) Correção gramatical de frases agramaticais e assemânticas: Neste subteste, são apresentadas à criança frases com incorreções tanto semânticas quanto gramaticais. A tarefa da criança é corrigir o erro gramatical sem alterar o erro semântico. Por exemplo, diante da frase "A menina subimos ao fundo do mar", a criança deve corrigir a gramaticalidade ignorando o erro semântico, dizendo "A menina subiu ao fundo do mar".

Instruções: Eu direi algumas frases erradas e você deve corrigir, deixando-as corretas. Mas não quero que você corrija o significado da frase, só o jeito de falar. Por exemplo, se eu disser: "A menina descemos para o telhado", você deve corrigir dizendo: "A menina desceu para o telhado". Eu sei que a gente não "desce para o telhado", a gente "sobe para o telhado". Mas eu não quero que você corrija isso, não quero que você corrija o significado da frase. A frase pode ser uma brincadeira, não tem problema.

Eu quero que você corrija somente o jeito de falar, porque não é certo falarmos "A menina descemos", mas sim "A menina desceu". Então vai ficar: "A menina desceu para o telhado". Agora vou falar outras frases e você vai corrigir só o jeito de falar, mas não o significado.

Itens de treino (aplicador pergunta e, após a resposta, explica como fica a frase correta):

a) $\mathrm{O}$ sol são preto. (Após a resposta da criança, dizer: A frase está errada porque não é "O sol são preto". A frase correta é "O sol é preto". Lembre-se de corrigir apenas o jeito de falar, mesmo que a frase seja mentira.)

b) A gato sabe voar. (Após a resposta da criança, dizer: A frase está errada porque não é "A gato 
sabe voar". A frase correta é "O gato sabe voar". (O aplicador também deve considerar correto se a criança disser "A gata sabe voar".)

c) A bruxa é bom. (Após a resposta da criança, dizer: A frase está errada porque não é "A bruxa é bom". A frase correta é "A bruxa é boa". Lembre-se de corrigir apenas o jeito de falar, mesmo que a frase seja mentira.)

(Se o aplicador achar que a criança ainda não entendeu, dar mais exemplos de treino.)

Agora você continua sozinho, eu não vou mais ajudar.

Itens de teste (aplicador anota a resposta da criança, mas não deve mais ajudar):
1. Ontem eu comemos prego.
2.Monstro é bonitos.
6. Galo botei ovos.
3.O lobo-mau são legal.
7. Os fogo está frio.
8. A Branca-de-Neve é feio.
4. Chuva é vermelha.
9. Lápis vou dormir.
5.Essa livro saiu correndo.
10. Essa livro saiu correndo.

4) Categorização de palavras: Neste subteste, é apresentada à criança uma folha com três colunas. A primeira contém um adjetivo (e. g., quente), a segunda, um substantivo (e. g., casa) e a terceira, um verbo (e. g., beberam). O aplicador mostra três palavras pertencentes às três categorias gramaticais selecionadas. Em seguida, explica à criança que, se a palavra for uma ação, deverá ficar abaixo de "beberam", na mesma coluna. Se for uma qualidade, deverá ficar abaixo de "quente". E, se for o nome de uma coisa, pessoa ou animal, deverá ficar abaixo de "casa". Em seguida, as crianças receberão 15 fichas, cada uma contendo uma palavra escrita, sendo 5 verbos, 5 substantivos e 5 adjetivos. $\mathrm{O}$ experimentador lerá cada palavra e pedirá à criança para categorizá-la, colocando-a na coluna correspondente. Assim, a cada palavra que o aplicador disser, a criança deverá apontar em que coluna ela deverá ficar.

Instruçôes: Veja esta folha com estas três palavras escritas. Aqui na primeira coluna está a palavra "quente", na segunda coluna, a palavra "casa" e, na terceira coluna, a palavra "beberam". Observe que a primeira palavra, "quente", é uma qualidade. A segunda palavra, "casa", é uma coisa, um objeto. E a terceira palavra, "beberam”, é uma ação, um verbo.
Eu vou dizer outras palavras para você, e você deve dizer se vai ficar junto com "quente", com "casa" ou com "beberam". Se for uma qualidade, deve ficar junto com "quente. Se for uma coisa, um nome, deve ficar junto com "casa". E se for uma ação, um verbo, deve ficar junto com "beberam". Então se eu disser "livro", deve ficar junto com "casa", porque é um nome, uma coisa. Se eu disser "dormiu", deve ficar junto com "beberam", porque é uma ação, um verbo. Se eu disser "bonito", deve ficar junto com "quente", porque é uma qualidade. Agora eu vou falar outras palavras e você vai dizer onde elas devem ficar.

Itens de treino (aplicador pergunta e, após a resposta, explica como fica a frase correta):

a) correu. (Após a resposta da criança, dizer: A palavra "correu" deve ficar junto com "bebemos", porque é uma ação, um verbo.)

b) alto. (Após a resposta da criança, dizer: A palavra "alto" deve ficar junto com "quente", porque é uma qualidade.)

c) relógio. (Após a resposta da criança, dizer: A palavra "relógio" deve ficar junto com "casa", porque é uma coisa, um nome.)

(Se o aplicador perceber que a criança não entendeu, deve fornecer mais exemplos.)

Agora você continua sozinho, eu não vou mais ajudar.

Itens de teste (aplicador anota a resposta da criança, mas não deve mais ajudar. Para facilitar a correção pelo aplicador, encontram-se descritas, entre parênteses, as categorias às quais as palavras pertencem):
1. Menino (substantivo)
9. Bola (substantivo)
2. Gostoso (adjetivo)
3. Muro (substantivo)
10. Macio (adjetivo)
4. Vestiram (verbo)
5. Cheiroso (adjetivo)
6. Andou (verbo)
7. Cachorro (substantivo)
11. Dançaram (verbo)
12. Brilhante (adjetivo)
13. Trem (substantivo)
14. Magro (adjetivo)
15. Brincou (verbo)

8. Escreveram (verbo)

O escore total na Prova de Consciência Sintática corresponde à soma dos acertos em cada subteste, totalizando um máximo possível de 55 acertos.

\section{Sobre os autores:}

Alessandra Gotuzo Seabra Capovilla é doutora em Psicologia Experimental, com Pós-Doutorado em Psicologia Cognitiva da Leitura, jovem pesquisadora (Fapesp), pesquisadora bolsista de Produtividade (CNPq) e professora do curso de Psicologia e Programa de Estudos Pós-Graduados em Psicologia da Universidade São Francisco.

Fernando C. Capovilla é doutor em Psicologia Experimental, livre-docente em Neuropsicologia, pesquisador nível 1 (CNPq), coordenador nacional do Programa de Treinamento Alfabetizadores (Capes), professor do Doutorado em Psicologia Experimental, chefe do Laboratório de Neuropsicolingüística Cognitiva Experimental e Divisão de Distúrbios de Comunicação e Linguagem (USP).

Joceli Vergínia Toledo Soares é psicóloga e pedagoga, mestre em Psicopedagogia pela Universidade de Santo Amaro. 


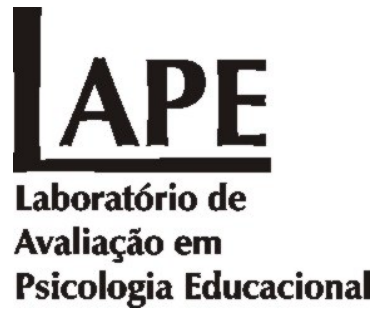

Programa de Estudos Pós-Graduados em Psicologia da Universidade São Francisco

Estudo de instrumentos de avaliação de processos cognitivos e afetivos envolvidos em situações de aprendizagem nos diversos contextos de escolarização. Envolve a participação de doutorandos, mestrandos e bolsistas de Iniciação Científica.

Professores responsáveis:

Dra. Acácia Aparecida Angeli dos Santos acacia.santos@saofrancisco.edu.br

Dr. Fermino Fernandes Sisto

fermino.sisto@saofrancisco.edu.br

Dra. Maria Cristina Rodrigues Azevedo Joly maria.joly@saofrancisco.edu.br 